Original Article

\title{
Trunk Control Ability after Minimally Invasive Lumbar Fusion Surgery during the Early Postoperative Phase
}

\author{
Jwo-Luen Pao, MD ${ }^{1,2)}$, Rong-Sen Yang, MD, PhD ${ }^{3,4)}$, Chen-Hsi Hsiao, PT, $\mathrm{MS}^{5 \text { ), }}$ \\ WeI-Li Hsu, PT, PhD ${ }^{5,6}$ * $^{*}$ \\ 1) Institute of Biomedical Engineering, National Taiwan University, Taiwan \\ 2) Division of Orthopedic Surgery, Department of Surgery, Far Eastern Memorial Hospital, Taiwan \\ 3) Department of Orthopedics, National Taiwan University Hospital, Taiwan \\ 4) Department of Orthopedics, College of Medicine, National Taiwan University, Taiwan \\ 5) School and Graduate Institute of Physical Therapy, College of Medicine, National Taiwan \\ University: Room 326, Floor 3, No. 17, Xuzhou Road, Zhongzheng District, Taipei City 100, Taiwan \\ 6) Physical Therapy Center, National Taiwan University Hospital, Taiwan
}

\begin{abstract}
Purpose] Lumbar fusion has been used for spinal disorders when conservative treatment fails. The minimally invasive approach causes minimal damage to the back muscles and shortens the postoperative recovery time. However, evidence regarding functional recovery in patients after minimally invasive lumbar spinal fusion is limited. The purpose of this study was to investigate how trunk control ability is affected after minimally invasive lumbar fusion surgery during the early postoperative phase. [Subjects and Methods] Sixteen patients and 16 age- and sex-matched healthy participants were recruited. Participants were asked to perform a maximum forward reaching task and were evaluated 1 day before and again 1 month after the lumbar fusion surgery. Center of pressure (COP) displacement, back muscle strength, and scores for the Visual Analog Scale, and Chinese version of the modified Oswestry Disability Index (ODI) were recorded. [Results] The healthy control group exhibited more favorable outcomes than the patient group both before and after surgery in back strength, reaching distance, reaching velocity, and COP displacement. The patient group improved significantly after surgery in all clinical outcome measurements. However, reaching distance decreased, and the reaching velocity as well as COP displacement did not differ before and after surgery. [Conclusion] The LBP patients with lumbar fusion surgery showed improvement in pain intensity 1 month after surgery but no improvement in trunk control during forward reaching. The results provide evidence that the back muscle strength was not fully recovered in patients 1 month after surgery and limited their ability to move their trunk forward.

Key words: Biomechanics, Postural balance, Low back pain
\end{abstract}

(This article was submitted Jan. 7, 2014, and was accepted Feb. 16, 2014)

\section{INTRODUCTION}

Lumbar spinal fusion surgery has been widely used to manage pain and neurological symptoms in LBP patients. The surgery usually eliminates symptoms successfully, with long-term consequences being considered of secondary importance. However, nearly one-third of patients undergo spine surgery again within 2 years after the first operation ${ }^{1)}$. Therefore, it is crucial to understand the characteristics of functional outcomes following postoperative sequelae of lumbar fusions.

The immediate effect of minimally invasive lumbar

*Correponding author. Wei-Li Hsu (E-mail: wlhsu@ntu.edu. tw)

C2014 The Society of Physical Therapy Science. Published by IPEC Inc. This is an open-access article distributed under the terms of the Creative Commons Attribution Non-Commercial No Derivatives (by-ncnd) License $<$ http://creativecommons.org/licenses/by-nc-nd/3.0/>. fusion is marked ${ }^{2,3)}$. Pain is diminished, and the unstable spinal segment is stabilized. However, limited back motion after spinal fusion can induce compensatory movement for the loss of spinal motion ${ }^{4}$. Only a few studies have addressed changes in muscle function ${ }^{5)}$ and functional performance ${ }^{6,7)}$ after lumbar spinal fusion surgery. Paraspinal muscle damage resulting from surgical procedures can induce muscle atrophy and fatty infiltrations ${ }^{8,9)}$. Previous research has shown the active roles of paraspinal muscles in stabilizing the spine ${ }^{10)}$. Thus, identifying the relationship between back muscle function and trunk control is criti$\mathrm{cal}^{11)}$.

To obtain spinal stability, it is essential to maintain a balanced interaction among the 3 subsystems: active (e.g., contractile tissues such as muscles and tendons), passive (e.g., the bony structure comprising the spine and ligaments), and neuromuscular control system (e.g., the neural control center and mechanoreceptors ${ }^{12,13)}$. Damage to or dysfunction in one subsystem requires the other 2 systems to compen- 
sate and may result in alteration in movement control for spinal stability. Regarding multi-joint coordination in spinal control, both biomechanical models and empirical evidence show that a combination of spinal muscle forces and appropriately timed muscle activity is necessary for maintaining spinal stability during movements ${ }^{14,15)}$. Altered lumbar and pelvis coordination in patients with LBP has also been shown during trunk forward bending ${ }^{16,17)}$, rising from a chair ${ }^{18)}$, and walking ${ }^{19)}$.

Previous research has indicated that altered intersegmental movement of the lumbar spine and pelvis could be explained by lack of adequate control of trunk extensors and potential trunk extensor muscle dysfunction ${ }^{17}$. Regarding the spinal stability system, minimally invasive spinal fusion can restore the function of passive spinal structures without extensive dissection of the active structure, such as paraspinal muscles. More importantly, after such a surgical procedure, patients can resume daily activities in a short amount of time. However, it remains unclear whether trunk control during forward movement is affected after a minimally invasive spinal fusion procedure, especially in the early postoperative phase.

Forward reaching is a common daily functional activity and has been considered an indicator of trunk control in patients with $\mathrm{LBP}^{10,17,20)}$. A forward reaching movement could involve the lumbar spine, hip, knee, and ankle joints. During forward bending, the moment acting on the back can reach over $300 \mathrm{Nm}$, which is equal to the moment generated by lifting a $15.7-\mathrm{kg}$ object from the floor ${ }^{21)}$. Thus, forward reaching movement is considered challenging for patients with LBP and could be used as an index to evaluate postoperation recovery. In clinical practice, patients are usually asked to protect their spine for 3 to 6 months after surgery. The safety margin for forward reaching in the early recovery phase must be identified.

The back muscles play a major role during trunk flexion contraction ${ }^{22,23)}$. Previous studies have also shown that lumbar movement is challenged most in the first $30^{\circ}$ of motion in trunk forward bending ${ }^{16,24-26)}$. The flexion of the trunk is initiated by the lumbar spine considerably earlier than that of the hip ${ }^{27)}$. Different reaching speeds may change the reaching distance ${ }^{28)}$. Moreover, a higher speed requires greater posture control and might alter muscle performance in the trunk and lower extremities. Speed of movement is often a crucial factor for movement control. How fast a patient should reach forward also must be identified.

Therefore, the purpose of this study was to investigate how trunk control such as in forward reaching, recover after minimally invasive spinal fusion during the early postoperative phase. We hypothesized that patients who have undergone spinal fusion still have decreased back muscle strength compared with healthy controls and that the ability to perform forward reaching thus declines after surgery. Specifically, reaching distance, reaching velocity, and center of pressure (COP) displacement were expected to be less in patients than in healthy participants. Moreover, trunk control ability would be associated with back muscle strength.

\section{SUBJECTS AND METHODS}

This study adhered to the principles of the Declaration of Helsinki for human research. Both the Research Ethics Committee of National Taiwan University Hospital and Far Eastern Memorial Hospital approved this study. Written informed consent was acquired for each participant.

Sixteen patients with LBP who underwent minimally invasive transforaminal lumbar interbody fusion (Mini-TLIF) in a medical center (the patient group) and 16 age- and sexmatched healthy adults (the control group) were recruited. The inclusion criteria for the patient group (patient group) before and after the Mini-TLIF operation were patients that (1) had a diagnosis of LBP requiring spinal fusion surgery provided by an orthopedic surgeon and verified with magnetic resonance imaging (MRI) data, (2) were scheduled for Mini-TLIF operation within 1 week, and (3) required an operation site that involved only the lumbar spine area. Patients with the following conditions were excluded: (1) scoliosis, (2) other neurological disorders, (3) self-reported impairment in daily activity, (4) leg length deficiency of over $2 \mathrm{~cm}$, and (5) a body mass index over 30 . The inclusion criteria of the age- and sex-matched control group (control group) were (1) no history of LBP within 1 year and (2) no previous operations in the spine and lower extremities. The exclusion criteria for the control group were the same as those for the patient group.

Participants provided written informed consent after the experimenter explained the study procedures. The patient group completed clinical outcome questionnaires regarding their health history and activity status 1 day before and 1 month after surgery (Pre-op and Post-op) at the bedside, including the Visual Analog Scale (VAS) ${ }^{29}$, and the Chinese version of the modified Oswestry Disability Index (ODI $)^{30}$ for disability assessment. The control group did not complete the questionnaires.

For both groups, hamstring flexibility was examined using the straight leg raise (SLR) test in the supine position. Back extensor muscle strength was measured using a back-leg-pull dynamometer in the standing position with the knee extended ${ }^{31)}$. The reaching distance during the forward reaching task was measured using a potentiometer, as shown in Fig. 1.

The pole of the potentiometer was set to shoulder height of the participant. Participants stood comfortably with their feet shoulder-width apart on a force plate (Kistler 9260AA6, Kistler Instrumente AG, Winterthur, Switzerland). The sampling rate of the ground reaction forces was set at $1,000 \mathrm{~Hz}$. Footprints were marked to ensure identical positioning for each trial. In the starting position, participants held both arms at a height equal to that of the acromion process, with the palms facing each other and middle fingers pointed at the contact plate of the potentiometer.

Participants were asked to maintain the starting position for 3 seconds and then reach forward as far as possible at a self-selected speed. Having reached the maximal displacement, the participants were asked to hold that position for another 3 seconds. All participants practiced several times before the data were collected, that is, until they felt famil- 


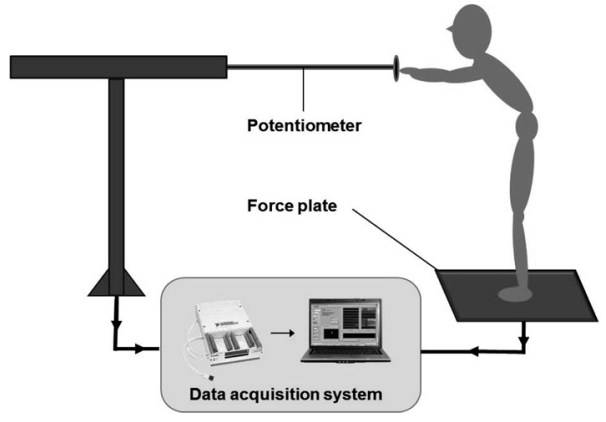

Fig. 1. Schematic diagram of the experiment setup.

iar with the reaching task. Five trials were recorded and then averaged across trials for the final result.

Forward reaching distance was measured using the voltage difference of the potentiometer between the onset and offset of the reaching movement. The reaching distance was then normalized to the foot length of each participant for an inter-person comparison. Forward reaching velocity was calculated to determine the onset and offset of the forwardreaching activity. The onset time was defined as the time at which the movement velocity was more than $10 \%$ of the peak velocity, whereas the offset time was defined as the time at which the movement velocity was less than $10 \%$ of the peak velocity (Fig. 2).

The weight-shifting ability was evaluated using force plate measurements of the center of pressure (COP) displacements. The COP was calculated using the ground reaction forces and moments recorded from the force plate by custom-written programs (MATLAB Version 7.0, MathWorks, Natick, MA, USA) and a zero-lag, fourth-order Butterworth filter using a $6-\mathrm{Hz}$ cutoff. The COP was separately calculated along the anteroposterior (AP) and mediolateral (ML) directions using the following equations:

$$
\begin{aligned}
& C O P_{A P}=\frac{F_{x}}{F_{z}}, \\
& C O P_{M L}=\frac{F_{y}}{F_{z}},
\end{aligned}
$$

where $\mathrm{F}_{\mathrm{x}}, \mathrm{F}_{\mathrm{y},}$ and $\mathrm{F}_{\mathrm{z}}$ are the ML, AP, and vertical ground reaction forces, respectively. The COP displacement was normalized to participant foot length, which indicates weight-shifting ability during forward reaching. The variance of the COP displacement in the ML direction during forward reaching was calculated to quantify the smoothness of forward reaching. COP variables were analyzed during the entire reaching phase.

The group differences in the demographic data between the control group and the patient group were examined using an independent ttest. The questionnaires (e.g., VAS and ODI) conducted for the patient group at the Pre-op and Post-op were examined by using a nonparametric test (the Wilcoxon test). Back muscle strength, forward reaching distance, reach mean and peak velocity, and COP displacement were examined using an independent t test for group

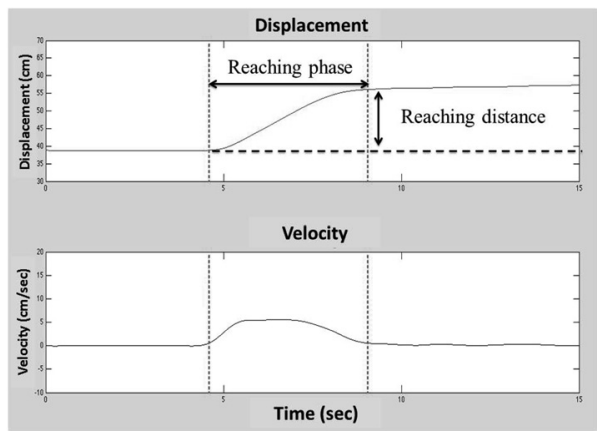

Fig. 2. A representative example of reaching displacement (upper) and velocity (lower) of forward reaching movement.

comparisons and a paired ttest for Pre-op and Post-op comparisons. A Pearson correlation was used to determine the correlations between back muscle strength and forward reaching outcome measures using pre- and postoperative data from the patient group.

The significance level was set at $\mathrm{p}<0.05$, and the sample size was estimated using our preliminary data based on the primary outcome - reaching distance. To determine the anticipated differences in reaching distance between groups for an $\alpha$ level of 0.05 , we required 12 participants in each group for approximately $80 \%$ power. Sixteen participants were recruited into each group to ensure sufficient power to detect differences. All statistical analyses were performed using the SPSS 18.0 package.

\section{RESULTS}

The participant's anthropometric and SLR test data are presented in Table 1. Both groups had similar ages, heights, weights, body mass indexes, and sex distributions. All clinical outcomes were significantly improved after surgery in the patient group (Table 2). After surgery, the VAS decreased by $5.31 \pm 3.46$ and ODI score decreased by $12.38 \pm 7.31$. The back muscle strength in the patient group was not significantly different at Pre-op and Post-op, and was significantly less than that in the control group.

The outcome measures of the forward reaching task are shown in Table 2. The reaching distance in the patient group was significantly less than that in the control group, both at Pre-op and Post-op. Moreover, the reaching distance significantly decreased at Post-op compared to Post-op in the patient group.

The reaching velocity and peak velocity were significantly slower both Pre-op and Post-op in the patient group compared with the control group (Table 2). Furthermore, the reaching velocity was not improved significantly Postop in the patient group.

The COP measures for the forward reaching task are shown in Table 2. The COP displacement in the AP direction was significantly less in the patient group compared with the control group, both Pre-op and Post-op. The COP displacement did not change at Post-op in the patient group. However, the variation of the COP displacement in the ML 
1168 J. Phys. Ther. Sci. Vol. 26, No. 8, 2014

Table 1. Characteristics of participants

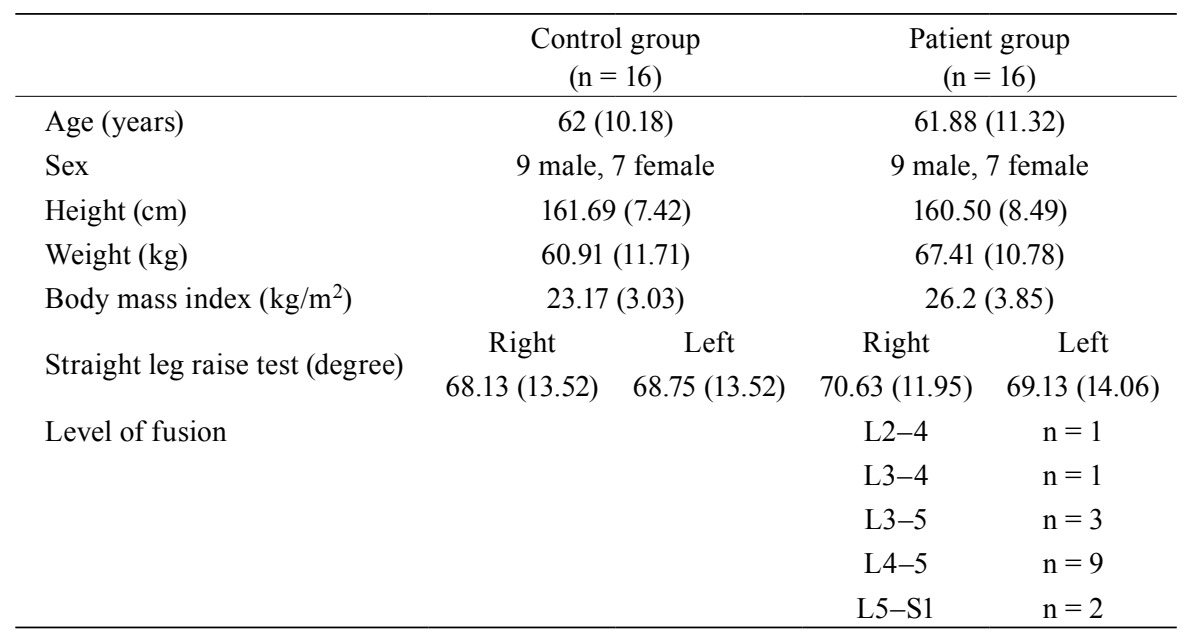

Values are means (SD)

Table 2. Clinical outcomes and reaching performance in the control group and patient group before (Pre-op) and after operation (Post-op)

\begin{tabular}{|c|c|c|c|c|c|c|}
\hline \multirow{2}{*}{ Clinical outcomes } & \multirow{2}{*}{\multicolumn{2}{|c|}{$\begin{array}{c}\text { Control } \\
\text { Mean (SD) }\end{array}$}} & \multirow{2}{*}{\multicolumn{2}{|c|}{$\begin{array}{c}\text { Pre-op } \\
\text { Mean (SD) }\end{array}$}} & \multicolumn{2}{|c|}{ Post-op } \\
\hline & & & & & \multicolumn{2}{|c|}{ Mean (SD) } \\
\hline VAS score & - & - & 7.13 & $(2.36)$ & 1.81 & $(1.76)$ \\
\hline ODI score & - & - & 22.69 & $(6.97)$ & 10.31 & $(6.47)$ \\
\hline Back muscle strength $(\mathrm{kg})$ & 70.50 & $(39.92)$ & 22.25 & $(16.31)$ & 23.25 & $(15.50)$ \\
\hline \multicolumn{7}{|l|}{ Reaching performance } \\
\hline Reaching distance (\% foot length) & 101.33 & $(16.31)$ & 73.06 & $(22.21)$ & 62.71 & $(22.25)$ \\
\hline Average reaching velocity $(\mathrm{cm} / \mathrm{s})$ & 5.95 & $(2.21)$ & 3.52 & $(1.60)$ & 3.42 & $(1.51)$ \\
\hline Peak reaching velocity $(\mathrm{cm} / \mathrm{s})$ & 11.04 & $(3.07)$ & 8.10 & $(2.62)$ & 8.23 & $(2.82)$ \\
\hline $\begin{array}{l}\text { COP displacement in anteroposterior direction } \\
\text { (\% foot length) }\end{array}$ & 33.89 & $(5.36)$ & 25.36 & $(7.17)$ & 23.27 & $(8.21)$ \\
\hline $\mathrm{COP}$ variation in mediolateral direction $\left(\mathrm{cm}^{2}\right)$ & 0.29 & $(0.14)$ & 0.20 & $(0.14)$ & 0.16 & $(0.15)$ \\
\hline
\end{tabular}

VAS, Visual Analog Scale; ODI, Chinese version of the Modified Oswestry Disability Index

direction was significantly less in the patient group compared with the control group only at Post-op.

The results of analysis of the correlation between back muscle strength and forward reaching performance in the patient group are shown in Table 3. The average reaching velocity and COP displacement in the anteroposterior direction were highly correlated with back muscle strength at Post-op. Only peak reaching velocity was highly correlated with back muscle strength at Pre-op.

\section{DISCUSSION}

The main purpose of this study was to investigate how trunk control ability was affected in the early recovery phase after Mini-TLIF surgery. The results showed that functional ability according to the clinical outcome questionnaires and pain scores of the patient group improved at 1-month post operation. However, forward reaching performance did not improve after surgery. The findings support our hypothesis that patients who undergo spinal fusion still have deficiencies in the back muscles that affect the ability to reach forward.

Minimally invasive surgery has several advantages compared with traditional open surgery, such as smaller surgical incisions and less paraspinal injury, which provide the benefits of less postoperative pain and a shorter recovery time ${ }^{32-35)}$. Similar to previous studies, this study showed that the wounds on the back had already healed at 1 month post operation. The patients felt no pain when pressing on the scar tissue. Most of the patients reported soreness and pain mainly from the deep layer of the operation site. The VAS score was higher than 5 in 13 out of 16 patients before surgery. After surgery, the VAS score of all patients dropped to less than 5. Only 1 patient reported an increased VAS score after surgery with a centralized painful area. Nevertheless, the data of this particular patient did not differ from that of other participants.

ODI scores for disability assessment also improved. These results were consistent with previous studies, which have stated that minimally invasive surgery can immedi- 
Table 3. Correlation coefficient $(r)$ between back muscle strength and reaching performance evaluation in the patient group at Pre-op and Post-op

\begin{tabular}{lcc}
\hline & $\begin{array}{c}\text { Back muscle strength } \\
\text { at Pre-Op (kg) }\end{array}$ & $\begin{array}{c}\text { Back muscle strength } \\
\text { at Post-Op (kg) }\end{array}$ \\
\hline Reaching distance (\% foot length) & $\mathrm{r}$ & $\mathrm{r}$ \\
Averaged reaching velocity $(\mathrm{cm} / \mathrm{s})$ & 0.056 & 0.453 \\
Peak reaching velocity $(\mathrm{cm} / \mathrm{s})$ & 0.527 & $0.810^{*}$ \\
COP displacement in anteroposterior direction & $0.697^{*}$ & 0.388 \\
(\% foot length) & 0.269 & $0.599^{*}$ \\
COP variation in mediolateral direction $\left(\mathrm{cm}^{2}\right)$ & -0.324 & -0.422 \\
\hline$* \mathrm{p}<0.05$ & &
\end{tabular}

ately alleviate the pain of patients ${ }^{32-34)}$. According to the answers provided for the clinical questionnaires, the patients were able to perform a higher load of daily activities more quickly after the operation than before the operation. However, the forward reaching distance of patients at 1 month post operation was still less than that of the control group. The trunk control ability of the LBP patients after surgery did not fully recover to the level of the healthy participants, even though the pain decreased. Thus, other factors such as muscle performance and movement stability must be further examined and are discussed as follows.

Forward reaching and COP displacement have been widely used to assess postural stability ${ }^{36-43)}$, and they were used to assess the trunk control ability in this study. COP displacement along the AP direction during a forward reach task decreases with age ${ }^{40,44)}$, or with balance disorders ${ }^{41,43)}$. Movement velocity ${ }^{28)}$ and variation of the movement path ${ }^{40)}$ have also been used to assess the quality of reaching performance. With the portable force plate, clinicians can easily evaluate patient's postural stability at bedside instead of in a biomechanics laboratory.

The patients in this study exhibited significantly shorter reaching distances than those of the controls, and they did not show improvements 1 month after surgery despite their reduced pain severity. Decreased mean and peak reaching velocity indicated that the patients were not confident when reaching forward to their maximum distance. Moreover, the variance of the COP displacement in the ML direction was significantly less in the patients than in the control group only at Post-op. According to the demographic data (Table 1), the physiological properties of the 2 groups were the same. Thus, forward reaching distance was not affected by hamstring flexibility, and the decline in reaching performance can be reasonably attributed to other factors. Fear avoidance could be a factor that caused the patients to adopt a conservative approach after surgery. Elevated fear avoidance has been shown to be associate with physical impairment in LBP patients ${ }^{45-47)}$ and to be significantly correlated with reduced lumbar flexor and extensor strength in patients with chronic $\mathrm{LBP}^{48,49)}$.

In clinical practice, patients are asked to protect their spine for 3 to 6 months after surgery by wearing a protective brace. This might be the reason that patients adopted a safe way to perform forward reaching at 1 month after sur- gery. Nevertheless, poor dynamic balance and trunk control after surgery could increase the risk of falling in the patient group during daily activities. Therefore, long-term followup in the patient group is necessary.

During forward reaching while standing, maintaining the COP within the stability boundary is a challenging task for trunk control. A person can perform a forward reaching task by using lumbar, pelvic, hip, or ankle or a combination of the joints. In a previous study, healthy younger adults reached with greater trunk flexion and less lower limb flexion than elderly adults ${ }^{50}$. The older population adopted a hip strategy but did not use an ankle strategy during balance recovery ${ }^{51)}$. A hip strategy keeps the center of mass away from the edge of the base of support. This study shows that the deficiencies in back muscles could lead patients to avoid using an ankle strategy and instead use a hip strategy to reach.

Forward reaching is considered to be an indicator of balance ability ${ }^{17)}$. Although reaching distance did not improve after surgery, patients who had greater back muscle strength could reach with a faster velocity and exhibited greater weight transfer ability in the COP displacement than patients who had less back muscle strength (Table 3). Given the current evidence of deficiencies in this patient population and the findings in this study, we recommend that clinicians assess back muscle function by using tests that challenge postural stability such as forward reaching.

Spinal stability and trunk control require a balanced interaction among active, passive, and neuromuscular subsystems ${ }^{12,13)}$. With increased awareness of the active roles of paraspinal muscles in stabilizing the spine ${ }^{10)}$, minimally invasive surgery can minimize the extent of paraspinal muscle injury ${ }^{52-55)}$. However, limited back motion and decreased muscle strength after spinal fusion may induce muscle atrophy and fatty infiltrations ${ }^{8}$. Paraspinal muscle damage caused by surgery has been found to accelerate muscle atrophy and fatty infiltrations. Therefore, whether minimally invasive lumbar fusion surgery will cause the same paraspinal muscle atrophy and fatty infiltration in the long term and how the decreased neuromuscular control of patients will correlate to the morphology changes in paraspinal muscles should be further monitored with MRI records in future research. Previous studies have shown that after spinal surgery, patients have weaker back muscle 
strength $^{56)}$ and experience changes in muscle activity, such as a delayed firing time and abnormal patterns ${ }^{24-26)}$. Therefore, the decline in trunk control while reaching may also be attributable to an overall decrease in neuromuscular control. Early rehabilitation in back muscle training should also be introduced after a Mini-TLIF surgery.

The findings of this study suggest possible back muscle impairment in patients after Mini-TLIF surgery. Despite recovery of functional ability and lessened pain, a lack of adequate early rehabilitation might cause a more severe secondary pathology in the future. Thus, the early use of static exercise to train the back muscles is vital for LBP patients after spine surgery. Compensatory movement patterns should be a cause for concern. Otherwise, this rehabilitative oversight might reduce the range of the stability boundary and increase the risk of falls in patients.

This study evaluated only muscle performance and movement quality during the forward reaching task and lacked of joint kinematic data. Because of the confined experiment space and limited time at the bedside, it was difficult to collect all kinematic data in a hospital setting. Moreover, the broad range in the patients' ages, occupations, and psychological problems might also be confounding factors. A subgroup analysis should be conducted with a large number of participants in a future study.

The patients' pain severity and daily activity functions improved at 1 month after Mini-TLIF surgery; however, the patients still showed deficiencies in their back muscle strengths and forward reaching performance. A compensatory movement pattern should be a source of concern because it might reduce the range of the stability boundary and increase the risk of falls in patients. These results suggest that LBP patients who undergo Mini-TLIF surgery might still be afraid of moving their trunk forward 1 month after surgery. Clinicians should focus on early back muscle training in LBP patients after lumbar fusion surgery to restore their back muscle function in the early recovery phase.

\section{ACKNOWLEDGEMENTS}

This work was supported by the National Science Council (NSC101-2320-B002-004-MY3) and National Taiwan University (NTU-CDP-101R7835, NTU-CDP-102R7835, NTU-CDP-103R7835).

\section{REFERENCES}

1) Martin BI, Mirza SK, Comstock BA, et al.: Are lumbar spine reoperation rates falling with greater use of fusion surgery and new surgical technology? Spine, 2007, 32: 2119-2126. [Medline] [CrossRef]

2) Carreon LY, Glassman SD, Howard J: Fusion and nonsurgical treatment for symptomatic lumbar degenerative disease: a systematic review of Oswestry Disability Index and MOS Short Form-36 outcomes. Spine J, 2008, 8: 747-755. [Medline] [CrossRef]

3) Chou R, Baisden J, Carragee EJ, et al.: Surgery for low back pain: a review of the evidence for an American Pain Society Clinical Practice Guideline. Spine, 2009, 34: 1094-1109. [Medline] [CrossRef]

4) Frymoyer JW, Hanley EN Jr, Howe J, et al.: A comparison of radiographic findings in fusion and nonfusion patients ten or more years following lumbar disc surgery. Spine, 1979, 4: 435-440. [Medline] [CrossRef]

5) Tarnanen $\mathrm{S}$, Neva $\mathrm{MH}$, Kautiainen $\mathrm{H}$, et al.: The early changes in trunk muscle strength and disability following lumbar spine fusion. Disabil Re- habil, 2013, 35: 134-139. [Medline] [CrossRef]

6) Videbaek TS, Bünger CE, Henriksen M, et al.: Sagittal spinal balance after lumbar spinal fusion: the impact of anterior column support results from a randomized clinical trial with an eight- to thirteen-year radiographic follow-up. Spine, 2011, 36: 183-191. [Medline] [CrossRef]

7) Pons T, Shipton EA: Multilevel lumbar fusion and postoperative physiotherapy rehabilitation in a patient with persistent pain. Physiother Theory Pract, 2011, 27: 238-245. [Medline] [CrossRef]

8) Kjaer P, Bendix T, Sorensen JS, et al.: Are MRI-defined fat infiltrations in the multifidus muscles associated with low back pain? BMC Med, 2007, 5: 2. [Medline] [CrossRef]

9) Chan ST, Fung PK, Ng NY, et al.: Dynamic changes of elasticity, crosssectional area, and fat infiltration of multifidus at different postures in men with chronic low back pain. Spine J, 2012, 12: 381-388. [Medline] [CrossRef

10) Hides JA, Stanton WR, McMahon S, et al.: Effect of stabilization training on multifidus muscle cross-sectional area among young elite cricketers with low back pain. J Orthop Sports Phys Ther, 2008, 38: 101-108. [Medline] [CrossRef]

11) Sung PS, Park HS: Gender differences in ground reaction force following perturbations in subjects with low back pain. Gait Posture, 2009, 29: 290-295. [Medline] [CrossRef]

12) Panjabi MM: The stabilizing system of the spine. Part I. Function, dysfunction, adaptation, and enhancement. J Spinal Disord, 1992, 5: 383-389, discussion 397. [Medline] [CrossRef]

13) Panjabi MM: The stabilizing system of the spine. Part II. Neutral zone and instability hypothesis. J Spinal Disord, 1992, 5: 390-396, discussion 397. [Medline] [CrossRef]

14) Granata KP, Wilson SE: Trunk posture and spinal stability. Clin Biomech (Bristol, Avon), 2001, 16: 650-659. [Medline] [CrossRef]

15) Cholewicki J, McGill SM: Mechanical stability of the in vivo lumbar spine: implications for injury and chronic low back pain. Clin Biomech (Bristol, Avon), 1996, 11: 1-15. [Medline] [CrossRef]

16) Esola MA, McClure PW, Fitzgerald GK, et al.: Analysis of lumbar spine and hip motion during forward bending in subjects with and without a history of low back pain. Spine, 1996, 21: 71-78. [Medline] [CrossRef]

17) Silfies SP, Bhattacharya A, Biely S, et al.: Trunk control during standing reach: a dynamical system analysis of movement strategies in patients with mechanical low back pain. Gait Posture, 2009, 29: 370-376. [Medline] [CrossRef]

18) Shum GL, Crosbie J, Lee RY: Three-dimensional kinetics of the lumbar spine and hips in low back pain patients during sit-to-stand and stand-tosit. Spine, 2007, 32: E211-E219. [Medline] [CrossRef]

19) Lamoth CJ, Meijer OG, Wuisman PI, et al.: Pelvis-thorax coordination in the transverse plane during walking in persons with nonspecific low back pain. Spine, 2002, 27: E92-E99. [Medline] [CrossRef]

20) Simmonds MJ, Olson SL, Jones S, et al.: Psychometric characteristics and clinical usefulness of physical performance tests in patients with low back pain. Spine, 1998, 23: 2412-2421. [Medline] [CrossRef]

21) Dolan P, Adams MA: The relationship between EMG activity and extensor moment generation in the erector spinae muscles during bending and lifting activities. J Biomech, 1993, 26: 513-522. [Medline] [CrossRef]

22) Hashemirad F, Talebian S, Hatef B, et al.: The relationship between flexibility and EMG activity pattern of the erector spinae muscles during trunk flexion-extension. J Electromyogr Kinesiol, 2009, 19: 746-753. [Medline] [CrossRef]

23) Jorgensen MJ, Marras WS, Gupta P, et al.: Effect of torso flexion on the lumbar torso extensor muscle sagittal plane moment arms. Spine J, 2003 , 3: 363-369. [Medline] [CrossRef]

24) Ahern DK, Follick MJ, Council JR, et al.: Comparison of lumbar paravertebral EMG patterns in chronic low back pain patients and non-patient controls. Pain, 1988, 34: 153-160. [Medline] [CrossRef]

25) Arendt-Nielsen L, Graven-Nielsen T, Svarrer H, et al.: The influence of low back pain on muscle activity and coordination during gait: a clinical and experimental study. Pain, 1996, 64: 231-240. [Medline] [CrossRef]

26) Radebold A, Cholewicki J, Polzhofer GK, et al.: Impaired postural control of the lumbar spine is associated with delayed muscle response times in patients with chronic idiopathic low back pain. Spine, 2001, 26: 724-730. [Medline] [CrossRef]

27) Pal P, Milosavljevic S, Sole G, et al.: Hip and lumbar continuous motion characteristics during flexion and return in young healthy males. Eur Spine J, 2007, 16: 741-747. [Medline] [CrossRef]

28) Kozak K, Ashton-Miller JA, Alexander NB: The effect of age and movement speed on maximum forward reach from an elevated surface: a study in healthy women. Clin Biomech (Bristol, Avon), 2003, 18: 190-196. [Medline] [CrossRef $]$ 
29) Bijur PE, Silver W, Gallagher EJ: Reliability of the visual analog scale for measurement of acute pain. Acad Emerg Med, 2001, 8: 1153-1157. [Medline] [CrossRef]

30) Fritz JM, Irrgang JJ: A comparison of a modified oswestry low back pain disability questionnaire and the quebec back pain disability scale. Phys Ther, 2001, 81: 776-788. [Medline]

31) Bethards $\mathrm{S}$, Everitt-Smith $\mathrm{S}$, Roberts $\mathrm{H}$, et al.: Intrarater test-retest reliability of an instrument used to measure back and leg strength. Isokinet Exerc Sci, 1995, 5: 31-35.

32) Rodríguez-Vela J, Lobo-Escolar A, Joven-Aliaga E, et al.: Perioperative and short-term advantages of mini-open approach for lumbar spinal fusion. Eur Spine J, 2009, 18: 1194-1201. [Medline] [CrossRef]

33) Pao JL, Chen WC, Chen PQ: Clinical outcomes of microendoscopic decompressive laminotomy for degenerative lumbar spinal stenosis. Eur Spine J, 2009, 18: 672-678. [Medline] [CrossRef]

34) Anand N, Baron EM, Bray RS: Benefits of the paraspinal muscle-sparing approach versus the conventional midline approach for posterior nonfusion stabilization: comparative analysis of clinical and functional outcomes. SAS J, 2007, 1: 93-99. [CrossRef]

35) Glassman SD, Carreon LY, Djurasovic M, et al.: Lumbar fusion outcomes stratified by specific diagnostic indication. Spine J, 2009, 9: 13-21. [Medline] [CrossRef]

36) Karlsson A, Frykberg G: Correlations between force plate measures for assessment of balance. Clin Biomech (Bristol, Avon), 2000, 15: 365-369. [Medline] [CrossRef]

37) Corriveau H, Hébert R, Raîche M, et al.: Evaluation of postural stability in the elderly with stroke. Arch Phys Med Rehabil, 2004, 85: 1095-1101. [Medline] [CrossRef]

38) Kyvelidou A, Harbourne RT, Shostrom VK, et al.: Reliability of center of pressure measures for assessing the development of sitting postural control in infants with or at risk of cerebral palsy. Arch Phys Med Rehabil, 2010, 91: 1593-1601. [Medline] [CrossRef]

39) Kyvelidou A, Harbourne RT, Stuberg WA, et al.: Reliability of center of pressure measures for assessing the development of sitting postural control. Arch Phys Med Rehabil, 2009, 90: 1176-1184. [Medline] [CrossRef]

40) Huang MH, Brown SH: Age differences in the control of postural stability during reaching tasks. Gait Posture, 2013, 38: 837-842. [Medline] [CrossRef]

41) Hsu WL, Yang YR, Hong CT, et al.: Ankle muscle activation during functional reach in hemiparetic and healthy subjects. Am J Phys Med Rehabil, 2005, 84: 749-755. [Medline] [CrossRef]

42) Rugelj D, Trontelj JV, Strojnik V: The influence of light hypothenar contact during a reaching movement on the centre of pressure (COP) forward displacement. PLoS ONE, 2013, 8: e55360. [Medline] [CrossRef]

43) Lin SI, Lin RM: Sensorimotor and balance function in older adults with lumbar nerve root compression. Clin Orthop Relat Res, 2002, (394): 146153. [Medline] [CrossRef]

44) Duncan PW, Weiner DK, Chandler J, et al.: Functional reach: a new clinical measure of balance. J Gerontol, 1990, 45: M192-M197. [Medline] [CrossRef]

45) Vlaeyen JW, Linton SJ: Fear-avoidance and its consequences in chronic musculoskeletal pain: a state of the art. Pain, 2000, 85: 317-332. [Medline] [CrossRef]

46) George SZ, Fritz JM, McNeil DW: Fear-avoidance beliefs as measured by the fear-avoidance beliefs questionnaire: change in fear-avoidance beliefs questionnaire is predictive of change in self-report of disability and pain intensity for patients with acute low back pain. Clin J Pain, 2006, 22: $197-$ 203. [Medline] [CrossRef]

47) George SZ: Fear: a factor to consider in musculoskeletal rehabilitation. J Orthop Sports Phys Ther, 2006, 36: 264-266. [Medline] [CrossRef]

48) Geisser ME, Haig AJ, Wallbom AS, et al.: Pain-related fear, lumbar flexion, and dynamic EMG among persons with chronic musculoskeletal low back pain. Clin J Pain, 2004, 20: 61-69. [Medline] [CrossRef]

49) Al-Obaidi SM, Nelson RM, Al-Awadhi S, et al.: The role of anticipation and fear of pain in the persistence of avoidance behavior in patients with chronic low back pain. Spine, 2000, 25: 1126-1131. [Medline] [CrossRef]

50) Cavanaugh JT, Shinberg M, Ray L, et al.: Kinematic characterization of standing reach: comparison of younger vs. older subjects. Clin Biomech (Bristol, Avon), 1999, 14: 271-279. [Medline] [CrossRef]

51) Hsu WL, Chou LS, Woollacott M: Age-related changes in joint coordination during balance recovery. Age (Dordr), 2013, 35: 1299-1309. [Medline] [CrossRef]

52) Tsutsumimoto $\mathrm{T}$, Shimogata M, Ohta H, et al.: Mini-open versus conventional open posterior lumbar interbody fusion for the treatment of lumbar degenerative spondylolisthesis: comparison of paraspinal muscle damage and slip reduction. Spine, 2009, 34: 1923-1928. [Medline] [CrossRef]

53) Isaacs RE, Podichetty VK, Santiago P, et al.: Minimally invasive microendoscopy-assisted transforaminal lumbar interbody fusion with instrumentation. J Neurosurg Spine, 2005, 3: 98-105. [Medline] [CrossRef]

54) Dhall SS, Wang MY, Mummaneni PV: Clinical and radiographic comparison of mini-open transforaminal lumbar interbody fusion with open transforaminal lumbar interbody fusion in 42 patients with long-term followup. J Neurosurg Spine, 2008, 9: 560-565. [Medline] [CrossRef]

55) Schwender JD, Holly LT, Rouben DP, et al.: Minimally invasive transforaminal lumbar interbody fusion (TLIF): technical feasibility and initial results. J Spinal Disord Tech, 2005, 18: S1-S6. [Medline] [CrossRef]

56) Kramer M, Katzmaier P, Eisele R, et al.: Surface electromyography-verified muscular damage associated with the open dorsal approach to the lumbar spine. Eur Spine J, 2001, 10: 414-420. [Medline] [CrossRef] 